Pesq. Vet. Bras. 29(11):943-950, novembro 2009

\title{
Desenvolvimento e avaliação de uma cepa knockout de Brucella abortus obtida pela deleção do gene virB10 ${ }^{1}$
}

\author{
Fabiane G. de Souza ${ }^{2 *}$, Ana L.A.R. Osório², Bárbara G. Csordas², Rafael Q. \\ Prado $^{3}$, Carina Elisei ${ }^{3}$, Cleber O. Soares ${ }^{3}$, Flábio R. Araújo ${ }^{3}$, Stênio P. \\ Fragoso ${ }^{4}$ e Grácia M.S. Rosinha ${ }^{3}$
}

\begin{abstract}
Souza F.G., Osório A.L.A.R., Csordas B.G., Prado R.Q., Elisei C., Soares C.O., Araújo F.R., Fragoso S.P. \& Rosinha G.M.S. 2009. [Development and evaluation of a strain of Brucella abortus gotten by the knockout of the virB10 gene.] Desenvolvimento e avaliação de uma cepa knockout de Brucella abortus obtida pela deleção do gene virB10. Pesquisa Veterinária Brasileira 29(11):943-950. Programa de Pós-Graduação, Mestrado em Ciência Animal, Faculdade de Medicina Veterinária e Zootecnia da Universidade Federal de Mato Grosso do Sul, Campo Grande, MS 79070-900, Brazil. E-mail: fabicientista@gmail.com

Brucella spp. are intracellular facultative gram-negative bacteria which are pathogenic for many species of mammals, causing brucellosis, a worldwide spread zoonosis. Therefore the search for more efficient alternatives of control, as the development of new potential immunogens is necessary. In this study, we knockouted virB10 from Brucella abortus S2308 strain, generating a mutant strain probably incapable to produce the corresponding native protein. The gene virB10 is part of an operon that codifies for type IV secretion system, which is essential for the intracellular survival and multiplication of the bacteria in host cells. The knockout was carried through by the construction of the suicidal plasmid pBlue: virB10: kan and eletroporation in eletrocompetent cells of $B$. abortus S2308, leading to the exchange of the wild gene for the interrupted gene, containing the gene of resistance to kanamycin, for double homologous recombination. BALB/c mice were inoculated with S19, RB-51, $\Delta$ virB10 strains of $B$. abortus and S2308 wild strain; the results demonstrated that the BALB/c mice inoculated with S19 and BALB/c mice inoculated with S2308 presented faster fall of trend line, when compared with the too much groups, for bacterial recovery (BR) and esplenic weight (EW) respectively. The groups that received $\Delta$ virB10 S2308 B. abortus and RB-51 demonstrated similar behavior for both the characteristics. In the sixth week postinoculation, the results for BR ( $\log U F C \pm$ standart deviations) and $E W$ (esplenic weight \pm standart deviations), respectively, showed: groups inoculated with strains S2308 $(4,44 \pm 1,97$ and $0,44 \pm 0,11)$, S19 $(1,83 \pm 2,54$ and $0,31 \pm 0,04)$, RB-51 $(0,00 \pm 0,00$ and $0,20 \pm 0,01)$ and $\Delta$ virB10 S2308 $(1,43 \pm 1,25$ and $0,19 \pm 0,03)$. Considered the bacterial clearance, all the groups differed statistical from the group that received S2308 $(p<0,0001)$, the group inoculated with $\Delta$ virB10 $S 2308$ B. abortus was similar to the $S 19$ group $(p=0,4302)$ and different of group RB-51 $(p=0,0063)$. The evaluation of the persistence of the strains showed that virB10 is essential for the maintenance of the virulence. These results support other studies concerning the immunogenic potential of this mutant strain.
\end{abstract}

INDEX TERMS: Brucella abortus, virB10 gene, knockout, virulence.

\footnotetext{
${ }^{1}$ Recebido em 28 de março de 2009.

Aceito para publicação em 10 de agosto de 2009.

2 Programa de Pós-Graduação, Mestrado em Ciência Animal, Faculdade de Medicina Veterinária e Zootecnia da Universidade Federal de Mato Grosso do Sul, Av. Felinto Muller 2443, Ipiranga, Campo Grande, MS 79070900, Brasil. "Autor para correspondência: fabicientista@gmail.com
}

\footnotetext{
${ }^{3}$ Embrapa Gado de Corte, BR 262 Km 4, Cx. Postal 154, Campo Grande, MS 79002-970, Brasil.

${ }^{4}$ Instituto de Biologia Molecular do Paraná, Rua Professor Algacyr Munhoz Mader 3775, Cidade Industrial de Curitiba (CIC), Curitiba, PR 81350-010, Brasil.
} 
RESUMO.- Brucella spp. são bactérias gram-negativas, intracelulares facultativas que são patogênicas para muitas espécies de mamíferos causando a brucelose, uma zoonose difundida mundialmente. Por isso a busca de alternativas de controle mais eficientes se faz necessário como o desenvolvimento de novas cepas que possam ser testadas como potenciais imunógenos. Neste estudo realizou-se a deleção do gene virB10 da cepa S2308 de Brucella abortus gerando uma cepa knockout provavelmente incapaz de produzir a proteína nativa correspondente. O gene virB10 faz parte de um operon que codifica para um sistema de secreção do tipo IV, essencial para a sobrevivência intracelular e multiplicação da bactéria em células hospedeiras. A deleção foi realizada pela construção do plasmídeo suicida pBlue:virB10:kan e eletroporação deste em células eletrocompetentes de $B$. abortus $\mathrm{S} 2308$, ocorrendo a troca do gene selvagem pelo gene interrompido, com o gene de resistência a canamicina, por recombinação homóloga dupla. Camundongos BALB/c foram inoculados com as cepas S19, RB-51, $\Delta$ virB10 de B. abortus e B. abortus $\mathbf{S} 2308$ selvagem; os resultados demonstraram que camundongos BALB/c inoculados com S19 e camundongos BALB/c inoculados com $\mathrm{S} 2308$ apresentaram queda mais rápida de linha de tendência, quando comparadas aos demais grupos, para recuperação bacteriana (RB) e peso esplênico (PE) respectivamente. Os grupos que receberam $\triangle$ virB10 S2308 de B. abortus e RB-51 demonstraram comportamento semelhante para ambas as características. Na sexta semana após a inoculação, os resultados para RB (log de UFC \pm desvio padrão) e PE (peso esplênico \pm desvio padrão), respectivamente, mostraram: grupos inoculados com as cepas S2308 $(4,44 \pm 1,97$ e $0,44 \pm 0,11)$, S19 $(1,83 \pm 2,54$ e $0,31 \pm 0,04), R B-51(0,00 \pm 0,00$ e $0,20 \pm 0,01)$ e $\Delta$ virB10 S2308 $(1,43 \pm 1,25$ e $0,19 \pm 0,03)$. Considerado o clearance bacteriano, todos os grupos diferiram estatisticamente do grupo que recebeu $S 2308(p<0,0001)$, o grupo inoculado com $\Delta$ virB10 S2308 de B. abortus foi semelhante ao grupo $S 19(p=0,4302)$ e diferente do grupo RB-51 $(p=0,0063)$. A avaliação da persistência revelou que o gene virB10 é essencial para a manutenção da virulência da bactéria. Os resultados obtidos possibilitarão que outras pesquisas sejam realizadas avaliando o potencial imunogênico desta cepa mutante.

TERMOS DE INDEXAÇÃO: Brucella abortus, gene virB10, deleção, virulência.

\section{INTRODUÇÃO}

Brucella spp. são bactérias gram-negativas, intracelulares facultativas que são patogênicas para muitas espécies de mamíferos incluindo o homem e que causam uma doença infecciosa crônica conhecida como brucelose, importante zoonose difundida mundialmente (Corbel 1997). Em humanos, a brucelose é uma doença debilitante caracterizada por diversas manifestações patológicas como febre ondulante, complicações osteoarticulares, endocardites e desordens neurológicas severas. Em ani- mais domésticos como bovinos, caprinos e ovinos a manifestação patológica proeminente é o aborto em fêmeas prenhes, devido a colonização da placenta, tecidos fetais e órgãos sexuais, e esterilidade em machos (Nicoletti 1989). Em bovinos a brucelose é causada por Brucella melitensis, biovar Abortus (= Brucella abortus) (Verguer et al. 1985). Em Brucella spp. a virulência está associada com a capacidade de multiplicação dentro das células hospedeiras. A sobrevivência e a multiplicação de Brucella spp. dependem eficientemente de evitar a fusão do fagossomo contendo a bactéria com o lisossomo, e a replicação ocorre em vesículas do reticulo endoplasmático. Os produtos gênicos que permitem Brucella spp. evadir e alcançar um nicho de replicação intracelular apropriado têm sido identificados (Pizarro-Cerdá et al. 1998).

As medidas de controle contra esta enfermidade baseiam-se no diagnóstico, eliminação dos animais infectados e vacinação. A vacinação contra infecções causadas por Brucella spp. é feita pela administração das cepas lisas atenuadas S19 de B. abortus e Rev.1 de B. melitensis. A cepa rugosa RB51 de $B$. abortus utilizada por EUA, Chile e Uruguai, atualmente foi também testada e aprovada para uso no Brasil. Porém esta cepa tem a desvantagem de ser resistente a rifampicina, um dos antibióticos usados no tratamento contra a brucelose humana (Poester et al. 2006). A cepa $S 19$ de $B$. abortus é efetiva contra a infecção por $B$. abortus em bovinos e a cepa Rev.1 de $B$. melitensis é efetiva contra a infecção por $B$. melitensis e $B$. ovis em cabras e ovelhas, respectivamente. Porém, ambas as vacinas possuem desvantagens (Cheville et al. 1993). Em função dos fatos expostos, grupos de pesquisadores têm produzido organismos mutantes pela deleção de genes essenciais ao metabolismo ou replicação de $B$. abortus, com a intenção de obter um sistema de imunização alternativo mais eficiente (Canavessi et al. 2004, Miyoshi et al. 2007).

O sistema de secreção do tipo IV é um dos cincos principais sistemas que são capazes de exportar moléculas relacionadas à virulência através da membrana de bactérias gram-negativas. Brucella spp. possui um sistema de secreção do tipo IV codificado por um operon virB o qual é essencial para a sobrevivência e multiplicação dentro das células hospedeiras (O'Collaghan et al. 1999). A região virB no genoma de $B$. abortus e $B$. suis é constituída por 12 janelas abertas de leitura (ORF, do inglês, Open Reading Frame) estruturadas em um operon, que é uma unidade genética de expressão coordenada (Boschiroli et al. 2002).

Rolán et al. (2009) em estudos com camundongos Igh6/- demonstraram que anticorpos não específicos podem reverter a deficiência desses camundongos no controle da replicação de mutantes virB sem, no entanto, afetar a cepa selvagem de Brucella abortus. Tais resultados sugerem que o sistema de secreção do tipo IV medeie a evasão de uma função natural anticorpo-dependente de clearance imune de $B$. abortus durante a persistência in vivo.

Cepas knockouts de Brucella spp., que apresentam deleções de genes os quais codificam um sistema de se- 
creção do tipo IV, perdem a habilidade de sobreviver e multiplicar em macrófagos e células epiteliais ( $O$ 'Collaghan et al. 1999, Foulongne et al. 2000). Em diferentes estudos, cepas knockouts para genes virB de $B$. abortus mostram ser incapazes de estabelecer uma infecção crônica em modelos com camundongos; resultados similares são encontrados em experimentos com B. suis (Boschiroli et al. 2002, Hong et al. 2000). Apesar da existência de diversos trabalhos demonstrando o efeito da deleção de genes virB na capacidade infectante de Brucella spp., não há relatos da utilização de mutantes virB de $B$. abortus como potenciais imunógenos. A ausência do gene virB10 em $B$. abortus diminui a capacidade do microrganismo replicar em macrófagos e, sobreviver em camundongos (Sieira et al. 2000). Neste estudo realizou-se o knockout do gene virB10 do genoma de $B$. abortus e foi avaliada a virulência desta cepa em camundongos BALB/c comparando-a com a obtida pelas cepas vacinais $\mathrm{S} 19$ e RB-51 e, a cepa selvagem $\$ 2308$ de $B$. abortus.

\section{MATERIAL E MÉTODOS}

Cepas bacterianas, plasmídeos e condições de cultivo

As cepas bacterianas e os plasmídeos utilizados neste estudo estão listados no Quadro 1. As cepas de Brucella abortus foram cultivadas em meio Brucella Broth (DIFCO) por três dias a $37^{\circ} \mathrm{C}$. Quando necessário o meio foi suplementado com ampicilina ou canamicina nas concentrações de $100 \mu \mathrm{g} / \mathrm{mL}$ e $25 \mu \mathrm{g} /$ $\mathrm{mL}$, respectivamente. Escherichia coli XL1-Blue foi cultivada a $37^{\circ} \mathrm{C}$ em meio Luria-Bertani (DIFCO) contendo canamicina a $50 \mu \mathrm{g} / \mathrm{mL}$ ou ampicilina a $100 \mu \mathrm{g} / \mathrm{mL}$ quando necessário. Para o preparo de meios sólidos utilizou-se a suplementação com 1,5\% de ágar bacteriológico. Quando necessário foi adicionado eritritol ao meio Brucella Broth (BB) ágar na concentração final de 0,1\%.

\section{Construção do plasmídeo suicida para o knockout do gene virB10 de Brucella abortus}

O plasmídeo suicida utilizado para a troca do gene selvagem virB10 de $B$. abortus pelo gene mutado foi obtido da maneira como se segue. Os primers utilizados no experimento foram desenhados utilizando o programa OLIGO (MS-DOS) tendo como base no DNA genômico de Brucella abortus visando a amplificação do fragmento de DNA correspondente ao gene virB10. Este gene, de 1167 pares de bases, foi amplificado pela técnica de reação em cadeia da polimerase (PCR, do inglês, Polymerase Chain Reaction ) a partir do DNA genômico de $B$. abortus S2308; os primers utilizados foram: virB10EcoF (5' GGC GAA TCC ATG ACA CAG GAA AAC ATT - 3') e virB10HindR (5' - GGC AAG CTT TCA CTT CGG TTT GAC ATC - 3'). O gene virB10 amplificado foi então digerido com as endonucleases de restrição EcoRI e Hindlll e ligado no vetor pBlueScriptKS (Stratagene) previamente digerido com as mesmas enzimas; resultando em pBlue:virB10 (Quadro 1). Para a realização do procedimento de subclonagem o plasmídeo pBlue:virB10 foi digerido com a endonuclease de restrição Mfel, que após o corte gera um fragmento de DNA com uma extremidade compatível a gerada pela enzima EcoRI. O plasmídeo pUC4K foi digerido com a enzima EcoRI liberando um fragmento de aproximadamente 1,3 kb correspondente ao gene de resistência a canamicina. Este fragmento foi ligado ao plasmídeo pBlue:virB10, previamente digerido, resultando no plasmídeo suicida pBlue:virB10:kan (Quadro 1) (Rosinha 2002).

\section{Obtenção dos mutantes de Brucella abortus por recombi- nação homóloga dupla}

Visando a obtenção de mutantes de $B$. abortus foram preparadas células eletrocompetentes de $B$. abortus S2308; com essa finalidade essa cepa de Brucella abortus foi cultivada em $200 \mathrm{~mL}$ de meio Brucella Broth por aproximadamente seis horas a $37^{\circ} \mathrm{C}$ até atingir a fase log de crescimento (densidade óptica de $600 \mathrm{~nm}, 0,4-0,6)$. As células bacterianas foram centrifugadas a $5000 \times$ g por 10 minutos, o pellet obtido foi lavado três vezes com água bi-destilada refrigerada contendo $10 \%$ de glicerol e ressuspendido em $0,65 \mathrm{~mL}$ desta mesma solução. Por fim, alíquotas de $0,05 \mathrm{~mL}$ foram estocadas imediatamente a $-80^{\circ} \mathrm{C}$. Cinco microgramas do plasmídeo suicida pBlue:virB10:kan foram adicionadas a $50 \mu \mathrm{L}$ de células eletrocompetentes de $B$. abortus em cubetas estéreis para eletroporação de $0,2 \mathrm{~cm}$ (BioRad Laboratories, Richmond, CA), e a eletroporação foi realizada com o aparato de transfecção Micro Pulser II (Bio Rad Labora-

Quadro 1. Cepas bacterianas e vetores usados neste estudo

\begin{tabular}{|c|c|c|}
\hline Cepas e plasmídeos & Características & Fonte \\
\hline $\begin{array}{c}\text { Cepas de Escherichia coli } \\
\text { E. coli XL1-Blue }\end{array}$ & $\begin{array}{c}\text { recA1 endA1gyrA96 thi-1 } \\
\text { hsdR17 supE44 relA1 } \\
\text { ac[F' proAB laclqZAM15 } \\
\text { Tn10 (Tetr)] }{ }^{\text {(a) }}\end{array}$ & Stratagene \\
\hline $\begin{array}{c}\text { Cepas de Brucella abortus } \\
\text { B. abortus } 2308 \\
\text { B. abortus DvirB10 } \\
\text { Plasmídeos }\end{array}$ & $\begin{array}{l}\text { Cepa selvagem, lisa, virulenta } \\
\operatorname{kan}^{r}(\mathbf{b}), \text { mutante virB10 de } 2308\end{array}$ & $\begin{array}{c}\text { Estoque do laboratório } \\
\text { Este estudo }\end{array}$ \\
\hline $\begin{array}{c}\text { pBlueScript }^{\circledR} \mathrm{KS} \\
\text { pUC4K } \\
\text { pBlue:virB10 }\end{array}$ & $\begin{array}{l}\text { ColE1 }(\mathbf{a}), \text { Amp }^{r}, \text { kan }^{r}(\mathbf{b}) \\
\text { pBlueScript } \\
{ }^{\circledR} \mathrm{KS} \\
\text { contendo o gene virB10 }\end{array}$ & $\begin{array}{l}\text { Stratagene } \\
\text { GE Healthcare } \\
\text { Este estudo }\end{array}$ \\
\hline pBlue:virB10:kan & $\begin{array}{l}\text { pBlue:virB10 contendo o } \\
\text { gene de canamicina }\end{array}$ & Este estudo \\
\hline
\end{tabular}

(a) características de cepas laboratoriais que carregam mutações que auxiliam na propagação de plasmídeos.

(b) $a m p^{r}$ - gene que confere resistência a ampicilina. $\mathrm{kan}^{r}$ - gene que confere resistência a canamicina. 
tories) a $25 \mu \mathrm{F}, 2,5 \mathrm{kV}$, e $400 \Omega$. Um mililitro de meio SOC ( $2 \%$ de triptona, $0,5 \%$ de extrato de levedura, $10 \mathrm{mM}$ de $\mathrm{NaCl}, 2,5 \mathrm{mM}$ $\mathrm{KCl}, 10 \mathrm{mM} \mathrm{MgCl}_{2}, 20 \mathrm{mM}$ de glicose) foi adicionado, e as células foram colocadas para crescer a $37^{\circ} \mathrm{C}$ sob agitação constante por 16 horas e plaqueadas em meio BB ágar contendo $25 \mu \mathrm{g} / \mathrm{ml}$ de canamicina. Após cinco dias de incubação a $37^{\circ} \mathrm{C}$, as colônias crescidas foram repicadas em placas contendo meio de cultivo BB ágar acrescido de $25 \mu \mathrm{g} / \mathrm{mL}$ de canamicina e $25 \mu \mathrm{g} /$ $\mathrm{mL}$ de ampicilina (Miyoshi et al. 2007).

\section{Análise por Southern blot de Brucella abortus mutante}

Com o intuito de comprovar geneticamente a troca ocorrida entre o gene virB10 da cepa selvagem de B. abortus (S2308) e o gene virB10 interrompido com o gene de canamicina, $10 \mu \mathrm{g}$ do DNA genômico isolado das cepas mutantes e selvagens de B. abortus foram digeridos com a enzima EcoRV e então colocados para migrar em gel de agarose a $1 \%$ para a realização da técnica de Southern blot (Miyoshi et al. 2007).

\section{Avaliação da virulência da cepa mutante em camundongos BALB/c}

A virulência da cepa mutante obtida foi determinada pela quantificação desta no baço de camundongos previamente infectados e pela avaliação da presença de alteração no peso dos baços. Camundongos BALB/c fêmeas de seis a oito semanas de idade foram divididos em quatro grupos de oito camundongos cada, e infectados na região intraperitoneal com $1 \times 10^{6}$ unidades formadoras de colônia (UFC) com as cepas S19, RB-51, S2308, AvirB10 (mutante para o gene virB10), separadamente. Uma, três e seis semanas após a infecção, os animais de cada grupo foram eutanasiados por deslocamento cervical e seus baços foram removidos, pesados e macerados em tampão fosfato-salino (PBS, do inglês, Phosphate Buffered Saline, $137 \mathrm{mM} \mathrm{NaCl}, 10 \mathrm{mM}$ Fosfato, $2,7 \mathrm{mM} \mathrm{KCl} \mathrm{e} \mathrm{pH}$ de 7,4 ), com o auxílio de uma peneira de aço. As diluições seriadas $10^{-2}$, $10^{-3}$ e $10^{-4}$ foram plaqueadas em meio BB canamicina para o grupo do mutante e em BB sem suplementações para o restante dos grupos. Três dias após a incubação em estufa a $37^{\circ} \mathrm{C}$, o número de UFC de cada grupo foi determinado para cada animal. Os resultados foram expressos como a média do log de UFC de cada cepa de B. abortus utilizada (Rosinha 2002).

\section{Análise estatística}

As análises estatísticas deste estudo foram realizadas por meio de ANOVA e do teste $\mathrm{t}$ de Student, utilizando-se o programa estatístico SAS (SAS 2005).

\section{RESULTADOS \\ Caracterização de Brucella abortus mutante obtida pela deleção do gene virB10}

Cinco clones de ambos os fenótipos canamicina resistente $\left(\mathrm{Kan}^{\mathrm{R}}\right)$ e ampicilina sensível $\left(\mathrm{Amp}^{\mathrm{S}}\right)$ ou canamicina resistente $\left(\operatorname{Kan}^{\mathrm{R}}\right)$ e ampicilina resistente $\left(\mathrm{Amp}^{\mathrm{R}}\right)$ foram selecionados como colônias que sofreram recombinação homóloga dupla e simples, respectivamente. Deste modo foi obtida uma cepa mutante de Brucella abortus a partir da deleção do gene virB10 da cepa selvagem $B$. abortus S2308. A mutação foi obtida por recombinação homóloga por troca do gene cromossomal utilizando o plasmídeo suicida pBlue:virB10:kan (Fig.1). O DNA cromossomal digerido com a enzima de restrição EcoRV

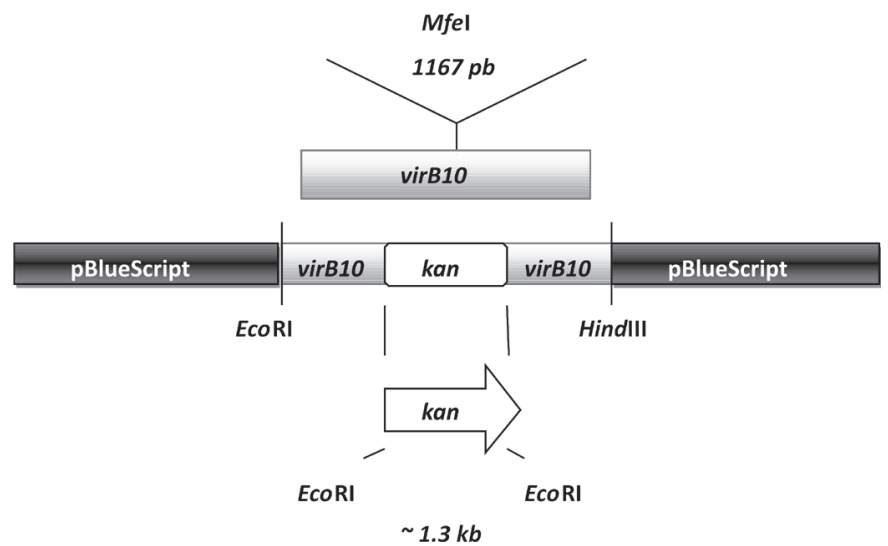

Fig.1. Representação esquemática do plasmídeo suicida pBlue: virB10 contendo o gene de canamicina interrompendo o gene virB10.

quando hibridizado com a sonda virB10 produziu um fragmento de aproximadamente $4,1 \mathrm{~kb}$ para $B$. abortus 2308 e uma banda de $5,4 \mathrm{~kb}$ para as colônias mutantes kan $^{R}$ $\mathrm{amp}^{\mathrm{S}}$ (três colônias dentre os cinco clones). A diferença de 1,3 kb observada entre o fragmento hibridizado virB10 presente nos mutantes $\mathrm{kan}^{\mathrm{R}}$ amp $\mathrm{m}^{\mathrm{S}}$ quando comparados com B. abortus 2308 foi de acordo com o tamanho correspondente a inserção do gene de canamicina dentro do gene virB10. Este perfil observado indica que houve recombinação homóloga dupla entre o gene virB10 interrompido pelo gene de resistência à canamicina do plasmídeo suicida com o gene selvagem do DNA cromossomal da bactéria. Um evento de recombinação homóloga simples ocorreu com os clones (duas colônias) que mostraram um fragmento de aproximadamente 8,3 $\mathrm{kb}$ que corresponde ao gene selvagem virB10 mais o gene da deleção plasmidial. Este resultado foi confirmado quando a sonda $a \mathrm{mp}^{R}$ hibridizou somente os fragmentos correspondentes a integração da deleção plasmidial (pBlue:virb10:kan) no cromossomo. Quando o gene de canamicina foi usado como sonda houve hibridização para os clones kan ${ }^{R} a m p^{S}$ e kan $^{R} a m p^{R}$ mas não para o DNA genômico da cepa selvagem $B$. abortus S2308 utilizado neste caso como um controle negativo. A diferença de tamanho observada entre os fragmentos dos clones kan $^{R}$ $a m p^{S}$ e $\operatorname{kan}^{R} a m p^{R}$ foi devido a integração da deleção plasmidial (pBlue:virb10:kan) no cromossomo da bactéria.

\section{Virulência da cepa mutante em camundongos BALB/c}

A virulência da cepa mutante $\Delta$ virB10 $\mathrm{S} 2308$ de $B$. abortus foi estudada em camundongos BALB/c e comparada à virulência da cepa selvagem $S 2308$ e cepas vacinais $\mathrm{S} 19$ e RB-51. O número de bactérias sobreviventes no baço dos animais infectados foi avaliado e os valores correspondentes à média de recuperação bacteriana em cada grupo podem ser observados no Quadro 2.

Conforme descrito na metodologia, os camundongos tiveram seus baços pesados e os resultados obtidos foram avaliados (Quadro 2). Foi observada esplenomega- 
Quadro 2. Peso esplênico (PE) e recuperação bacteriana (RB) no baço de camundongos $B A L B / c$ inoculados com a cepa mutante $\Delta$ virB10 S2308 de Brucella abortus, a cepa virulenta S2308 e as cepas vacinais RB-51 e S19. Valores expressos como a média do log de UFC \pm desvio padrão

(RB) e peso dos baços(em gramas) \pm desvio padrão (PE)

\begin{tabular}{|c|c|c|c|c|c|c|}
\hline \multirow[t]{3}{*}{ Inóculos } & \multicolumn{6}{|c|}{ Semanas após a inoculação } \\
\hline & \multicolumn{2}{|c|}{$1^{\underline{a}}$} & \multicolumn{2}{|c|}{$3^{\mathrm{a}}$} & \multicolumn{2}{|c|}{$6^{\underline{a}}$} \\
\hline & $\begin{array}{c}\text { PE } \\
\text { (peso dos } \\
\text { baços } \pm \text { desvio } \\
\text { padrão) }\end{array}$ & $\begin{array}{c}\text { RB } \\
\text { (log de UFC } \pm \\
\text { desvio padrão) }\end{array}$ & $\begin{array}{c}P E \\
\text { (peso dos } \\
\text { baços } \pm \text { desvio } \\
\text { padrão) }\end{array}$ & $\begin{array}{c}\text { RB } \\
\text { (log de UFC } \pm \\
\text { desvio padrão) }\end{array}$ & $\begin{array}{c}\text { PE } \\
\text { (peso dos } \\
\text { baços } \pm \text { desvio } \\
\text { padrão) }\end{array}$ & $\begin{array}{c}\text { RB } \\
\text { (log de UFC } \pm \\
\text { desvio padrão) }\end{array}$ \\
\hline S2308 & $0,70 \pm 0,09$ & $7,34 \pm 0,12$ & $1,06 \pm 0,15$ & $6,37 \pm 0,37$ & $0,44 \pm 0,11$ & $4,44 \pm 1,97$ \\
\hline S19 & $0,33 \pm 0,07$ & $7,39 \pm 0,21$ & $0,87 \pm 0,23$ & $6,12 \pm 0,17$ & $0,31 \pm 0,04$ & $1,83 \pm 2,54$ \\
\hline RB-51 & $0,15 \pm 0,01$ & $3,95 \pm 0,45$ & $0,19 \pm 0,03$ & $2,98 \pm 0,26$ & $0,20 \pm 0,01$ & $0,00 \pm 0,00$ \\
\hline$\Delta$ virB10 S2308 & $0,18 \pm 0,02$ & $6,29 \pm 0,24$ & $0,16 \pm 0,02$ & $4,42 \pm 0,24$ & $0,19 \pm 0,03$ & $1,43 \pm 1,25$ \\
\hline
\end{tabular}

UFC = Unidade Formadora de Colônia. BALB/c = Linhagem de camundongos isogênicos.

lia nos animais que foram inoculados com a cepa virulenta $\mathrm{S} 2308$ de B. abortus.

Quando avaliados recuperação bacteriana e peso esplênico em função do tempo pós- inoculação observou-
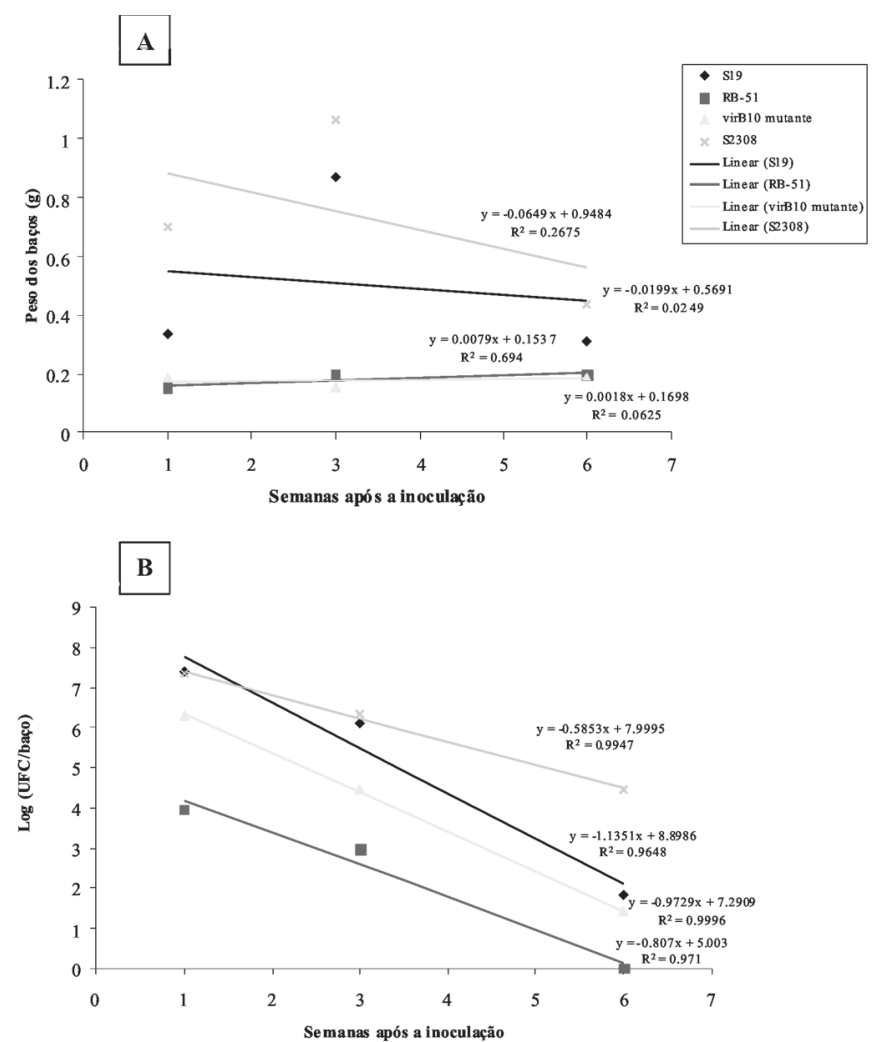

Fig.2. Tendências de peso esplênico $(A)$ e recuperação das cepas (B) de Brucella abortus $\mathrm{S} 2308$ selvagem, cepas vacinais $\mathrm{S} 19$ e RB-51 e, a cepa mutante $\Delta$ virB10 de $B$. abortus $\mathrm{S} 2308$ no baço de camundongos BALB/c infectados uma, três e seis semanas após a inoculação.Fig. 3. Tendência de recuperação das cepas Brucella abortus 2308 selvagem, cepas vacinais $\mathrm{S} 19$ e RB-51 e, a cepa mutante $\Delta$ virB10 de B. abortus $\mathrm{S} 2308$ no baço de camundongos BALB/c infectados (Painel A) e tendência de peso esplênico destes grupos uma, três e seis semanas após a inoculação (Painel B). Os pontos no gráfico correspondem as médias dos grupos em cada intervalo de tempo analisado. se que os grupos apresentaram linhas de tendência diferenciadas. Os camundongos foram inoculados por via intraperitoneal com $1 \times 10^{6}$ UFC de cada inóculo já mencionado. As linhas de tendência expressas correspondem à média do peso dos baços $(\mathrm{g})$ para cada grupo $(\mathrm{n}=8)$ $\mathrm{P}<0,05$ (Fig.2A) e à média do log de UFC para cada grupo $(n=8) P<0,05$ (Fig.2B).

\section{DISCUSSÃO}

As proteínas VirB, envolvidas no processo de replicação intracelular, são consideradas um fator de virulência em Brucella spp. e fazem parte do sistema de secreção do tipo IV que, aliado ao LPS, é o principal fator de virulência (Ding et al. 2003, Lapaque et al. 2005). Para que ocorra a sobrevivência intracelular e a multiplicação de $B$. suis, $B$. abortus e $B$. melitensis foi demonstrada a essencialidade de genes virB (Boschiroli et al. 2002, Wu et al. 2006), a qual está envolvida no amadurecimento dos vacúolos parasitóforos, possibilitando sua interação estável com o retículo endoplasmático rugoso e o escape da via de degradação, gerada pela fusão com lisossomos (Comerci et al. 2001, Celli \& Gorvel 2004). Mutantes em diferentes genes virB já foram atenuados, sendo a virulência restabelecida com plasmídeo contendo toda a região virB (O'Collaghan et al. 1999).

Dentre as possíveis formas de vacinas estudadas contra Brucella abortus, a estratégia que vem sendo amplamente utilizada é a obtenção de cepas geneticamente modificadas, por meio da deleção de genes supostamente envolvidos na virulência. Para atingir este fim, podem ser utilizadas varias técnicas, sendo a mais difundida, a utilização da recombinação homóloga dupla como recurso genético para obtenção destes mutantes. $O$ desenvolvimento de vacinas vivas deletadas tem sido avaliado para Brucella spp. (Canavessi et al. 2004, Miyoshi et al. 2007) e muitos outros patógenos como, por exemplo, Mycobacterium tuberculosis (Pavelka et al. 1999).

Neste estudo o gene virB10 de Brucella abortus foi deletado por meio da construção de um plasmídeo suicida contendo o gene interrompido, incapaz de expressar o gene, o qual foi introduzido na cepa selvagem S2308 de $B$. abortus e por recombinação homóloga foi gerada uma 
cepa mutante desta bactéria. VirB10 é um membro do aparato de transporte que tem homólogos em sistemas de secreção do tipo IV de diversos microorganismos (Christie 1997, Covacci et al. 1999). Este gene codifica uma proteína de membrana que tem um domínio periplasmático C-terminal, como mostrado em experimentos de fusão de PhoA (Das e Xie 1998). Cepa knockout de $B$. abortus obtida por deleção do gene virB10 de seu genoma apresentou sobrevivência intracelular diminuída em células do tipo HeLa; os resultados obtidos também indicam que virB10 e seqüências posteriores (virB11-ORF 12ORF13) são essenciais para a patogênese de Brucella spp. em camundongos e sugerem que a integridade do operon virB é requerida para virulência do tipo selvagem. Estudos com este gene mostraram que a ausência deste no genoma de $B$. abortus impossibilita cepas knockouts de replicar em macrófagos e sobreviver em camundongos (Sieira et al. 2000).

Em experimento realizado utilizando mutantes para os genes virB1 e virB2 de $B$. abortus observou-se que VirB1 e VirB2 são essenciais para a replicação intracelular em macrófagos do tipo J774 (Hartigh et al. 2004). Em estudos com mutantes para o gene virB4 de $B$. abortus foi verificado que este possui importante função no crescimento intracelular e na virulência em camundongos (Watarai et al. 2002).

Uma cepa mutante $B$. abortus para o gene vacB, um gene envolvido na expressão de genes vir, foi avaliada quanto a virulência em camundongos BALB/c e foram encontrados números reduzidos de UFC em comparação com os valores obtidos da cepa virulenta selvagem, porém esses resultados não foram significativos estatisticamente (Miyoshi et al. 2007).

Por todas as descobertas que mostram a relação dos genes virB, de Brucella spp., na virulência desta bactéria, comprova-se a sua importância nos mecanismos de desenvolvimento da brucelose; assim como a possibilidade de serem utilizados como potenciais imunógenos. Neste trabalho foi possível a obtenção de uma cepa mutante de Brucella abortus pela deleção do gene virB10. Esta cepa foi avaliada quanto à virulência em camundongos BALB/ $C$ e os resultados foram comparados a aqueles das cepas vacinais S19, RB-51 e a cepa selvagem S2308 de B. abortus. $\mathrm{O}$ número de bactérias sobreviventes no baço dos animais infectados foi avaliado uma, três e seis semanas pós-infecção. Este intervalo de tempo foi escolhido baseando-se no conhecimento de que a proteção contra bactérias intracelulares é mediada por ativação de macrófagos, também foram levados em consideração estudos os quais comprovam que a imunidade celular gerada pela ativação de macrófagos, durante a infecção por Brucella spp., declina de três a quatro semanas após a infecção (Baldwin 2002). Em trabalhos já realizados, intervalos de tempo similares foram adotados.

Uma semana após a infecção, comparando as cepas, $\Delta v i r B 10$ S2308 de B. abortus e RB-51 apresentaram diferença estatística quando comparadas entre si e à cepa selvagem S2308. A recuperação da cepa S19 mostrouse semelhante estatisticamente, ao nível de significância de 5\%, à cepa selvagem S2308 e diferente dos outros grupos $(p=0,9261)$. O mesmo padrão de recuperação foi observado três semanas após a infecção. Sieira et al. (2000) em seu trabalho com $\Delta$ virB10 2308 de B. abortus observou que o número de bactérias recuperadas do baço de camundongos inoculados com mutantes apolares de virB10 foi significativamente mais baixo $(p<0,05)$ do que o número recuperado de camundongos inoculados com a cepa selvagem, o que está de acordo com o encontrado em nossos resultados sendo o mutante $\Delta$ virB10 S2308 também apolar.

Hartigh et al. (2004) visando determinar o modo como os genes virB1 e virB2 são necessários para a persistência de $B$. abortus in vivo testaram a habilidade de estabelecimento da infecção e persistência em camundongos $\mathrm{BALB} / \mathrm{c}$ de mutantes polares e apolares para estes genes. A recuperação de UFC bacteriana foi observada uma, três e oito semanas após a inoculação. Uma semana após a infecção a cepa virulenta $\$ 2308$ foi recuperada em números seis a oito vezes maiores que os mutantes polares para virB1 e virB2 e, mutante apolar virB2.

Números duas vezes maiores foram encontrados quando comparados aqueles do mutante apolar para virB1. Três semanas após a infecção um padrão semelhante ao da primeira semana, de recuperação foi observado. Oito semanas após a infecção os números de UFC de mutantes polares para virB1 e virB2 e, mutante apolar virB2 foram três a quatro log menores do que aqueles da cepa virulenta selvagem S2308 e mutante apolar para virB1. Este trabalho sugere que VirB2 é essencial para a sobrevivência in vivo, enquanto VirB1 e dispensável para a persistência da infecção em camundongos.

No estudo presente, na sexta semana após a infecção, a diferença observada foi significativa quando os grupos infectados com $\Delta$ virB10 S2308 de B. abortus, S19 e RB-51 foram comparados ao grupo infectado com a cepa selvagem S2308 (a comparação entre as cepas mutante e selvagem apresentou $p<0,0001$ ). Os grupos S19 e RB-51 diferiram estatisticamente $(p=0,0005)$. Por outro lado o grupo infectado com a cepa mutante apresentou semelhança ao grupo $S 19(p=0,4302)$ e diferença estatística quando comparado ao grupo RB-51 $(p=0,0063)$. Esses resultados de clearance estão de acordo com resultados obtidos em experimentos com outros genes relacionados à virulência de Brucella spp. (Hartigh et al. 2004). Yang et al. (2006) relataram que a cepa mutante $\triangle z n u A$ foi atenuada em camundongos BALB/c. O gene znuA expressa uma proteína relacionada ao sistema de transporte de $\mathrm{Zn}^{+2}$, que é um mineral essencial para a bactéria com função estrutural e como cofator catalítico. Kahl-McDonagh e Ficht (2006), em experimentos com mutantes, observaram que mutantes de $B$. abortus e $B$. melitensis para o gene virB2 foram atenuados, mas de forma moderada quando comparados à cepa virulenta S2308, uma vez que outros mutantes no mes- 
mo experimento apresentaram mais rápido clearance. Paulley et al. (2007) para avaliar a função potencial do gene bhuA, que expressa um transportador de grupo heme, na patogênese e no transporte de grupo heme durante a permanência em hospedeiros mamíferos avaliou as propriedades de virulência de mutantes para este gene em cultura de macrófagos murinos e também em camundongos $\mathrm{BALB} / \mathrm{c}$. Tanto em macrófagos quanto em camundongos os mutantes bhuA exibiram significativa atenuação quando comparados à cepa virulenta selvagem S2308.

De acordo com os dados obtidos, o grupo infectado com $\Delta$ virB10 S2308 de B. abortus não apresentou esplenomegalia, esta que foi observada no grupo infectado com a cepa selvagem S2308; isto está em concordância aparente com os dados obtidos de recuperação bacteriana. Bactérias do gênero Brucella spp., ao difundir-se para tecidos dos hospedeiros, colonizam principalmente órgãos ricos em células do sistema mononuclear fagocitário, quais sejam, baço, fígado e linfonodos, onde podem acarretar alterações inflamatórias e anatomo-patológicas caracterizadas por granulomas difusos levando à esplenomegalia, hepatomegalia e, às vezes, hiperplasia linfóide (Bishop et al. 1994).

O grupo inoculado com a cepa $\mathrm{S19}$, quanto à recuperação bacteriana, apresentou queda mais rápida de persistência quando comparado aos demais grupos. Contudo esse comportamento não foi o mesmo para a média dos pesos dos baços dos animais inoculados, neste caso o grupo inoculado com a cepa selvagem S2308 foi o que apresentou linha de tendência com queda mais rápida (Fig.2A). Em ambos os casos, e com maior precisão para o peso esplênico, o grupo inoculado com $\Delta$ virB10 S2308 de $B$. abortus apresentou linha de tendência com comportamento semelhante ao inoculado com a cepa vacinal RB-51.

Esta cepa $\Delta$ virB10 S2308 de B. abortus futuramente poderá ser testada como nova cepa vacinal na busca de alternativas mais eficientes no controle da brucelose.

\section{CONCLUSÕES}

Neste trabalho foi possível a obtenção de cepas mutantes de Brucella abortus pelo knockout do gene virB10. A avaliação desta cepa em camundongos BALB/c comparando-a com a obtida pelas cepas vacinais $\mathrm{S} 19$ e RB-51 e, também com a cepa selvagem S2308 de B. abortus revelou que o gene virB10 é essencial para a manutenção da virulência da bactéria.

Agradecimentos.- Este trabalho foi financiado pela Fundação de Apoio ao Desenvolvimento do Ensino, Ciência e Tecnologia do Estado de Mato Grosso do Sul (FUNDECT) e Conselho Nacional de Desenvolvimento Científico e Tecnológico (CNPq). Agradecemos ao Dr. Roberto Torres, pesquisador da Embrapa Gado de Corte, pelo suporte na análise dos resultados.

\section{REFERÊNCIAS}

Baldwin C.L. 2002. Immune response overview. Vet. Microbiol. 90:365366.
Bishop G.C., Bosman P.P. \& Herr S. 1994. Bovine Brucellosis, p.10531066. In: Coetzer J.A.N., Thomson G.R. \& Tustin R.C. (Eds), Infectious Diseases of Livestock. University Press, College Station, Texas.

Boschiroli M.L., Ouahrani-Bettache S., Foulongne V., MichauxCharachon S., Bourg G., Allardet-Servent A., Cazevieille C., Liautard J.P., Ramuz M. \& O'Collaghan D. 2002. The Brucella suis virB operon is induced intracellulary in macrophages. Proc. Natl Acad. Sci. 99: 1544-1549.

Canavessi A.M.O., Jerome H., Gatti N.L. \& Splitter G.A. 2004. The role of integrase/recombinase xerD and monofunctional biosynthesis peptidoglycan transglycosylase genes in the pathogenicity of Brucella abortus infection in vitro and in vivo. Microb. Pathog. 37:241251.

Celli J. \& Gorvel J. 2004. Organelle robbery: Brucella interactions with the endoplasmic reticulum. Curr. Opin. Microbiol. 7:93-97.

Cheville N.F., Stevens M.G., Jesen A.E., Tatum F.M. \& Halling S.M. 1993. Immune responses and protection against infection and abortion in cattle experimentally vaccinated with mutants strains of Brucella abortus. Am. J. Vet. Res. 54:1591-1597.

Christie P.J. 1997. Agrobacterium tumefaciens T-complextransport apparatus: a paradigma for a new family of multifunctional transporters in eubacteria. J. Bacteriol. 179:3085-3094.

Comerci D.J., Martinez-Lorenzo M.J., Sieira R., Gorvel J.P. \& Ugalde R.A. 2001. Essencial role of the VirB machinery in the maturation of the Brucella abortus-containing vacuole. Cell Microbiol. 3:159-168.

Corbel M.J. 1997. Brucellosis: an overview. Emerg. Infect. Dis. 3:213221.

Covacci A., Telford J.L., Del Giudice G., Parsonnet J. \& Rappuoli R. 1999. Helicobacter pylori virulence and genetic geography. Science 284:1328-1333.

Das A. \&. Xie Y.H. 1998. Construction of transposon Tn3PHOa: Its application in defining the membrane topology of the Agrobacterium tumefaciens DNA transfer proteins. Mol. Microbiol. 14:405-414.

Ding Z., Atmakuri K. \& Christie P.J. 2003. The outers and ins of bacterial type IV secretion substrates. Trends Microbiol. 11:527-535.

Foulongne V., Bourg G., Cazevielle C., Michaux-Charachon S. \& O'Collaghan D. 2000. Identification of Brucella suis genes affecting intracellular survival in an in human macrophage infection model by signature-tagged transposon mutagenesis. Infect. Immun. 68:12971303.

Hartigh A.B. Den, Sun Y-H., Sondervan D., Heuvelmans N., Reinders M.O., Ficht T.A. \& Tsolis R.M. 2004. Diferential requirements for VirB1 and VirB2 during Brucella abortus infection. Infect. Immun. 72:51435149.

Hong P.C., Tsolis R.M. \& Ficht T.A. 2000. Identification of genes required for chronic persistence of Brucella abortus in mice. Infect. Immun. 68:4102-4107.

Kahl-McDonagh M.M. \& Ficht T.A. 2006. Evaluation of protection afforded by Brucella abortus and Brucella melitensis unmarked deletion mutants exhibiting different rates of clearance in BALB/c. Infect. Immun. 74:4048-4057.

Lapaque N., Moryon I., Moreno E. \& Gorvel J.P. 2005. Brucella lipopolysaccharide acts as virulence factor. Curr. Opin. Microbiol. 8:6066.

Miyoshi A., Rosinha G.M.S., Camargo I.L.B.C., Trant C.M.C., Cardoso F.C., Azevedo V. \& Oliveira S.C. 2007. The role of the vacB gene in the pathogenesis of Brucella abortus. Microbes Infect. 9:375-381.

Nicoletti P.L. 1989. Relationship between animal and human disease, p.41-51. In: Young E.J. \& Corbel M.J. (Eds), Brucellosis: Clinical and laboratory aspects. CRC Press Inc., Boca Raton.

O'Collaghan D., Cazevielle C., Allardet-Servent A., Boschiroli M.L., Bourg G., Foulongne V., Frutos P., Kulakov Y. \& Ramuz M. 1999. A homologue of Agrobacterium tumefaciens VirB and Bordetella pertussis Ptl 
type IV secretion systems is essential for intracellular survival of Brucella suis. Mol. Microbiol. 33:1210-1220.

Paulley J.T., Anderson E.S. \& Roop II R.M. 2007. Brucella abortus Requires the Heme Transporter BhuA for Maintenance of Chronic Infection in BALB/c Mice. Infect. Immun. 75:5248-5254.

Pavelka Jr M.S. \& Jacobs Jr W.R. 1999. Comparasion of the construction of unmarked deletion mutations in Mycobacterium smegmatis, Mycobacterium bovis Bacillus Calmette-Guerin, and Mycobacterium tuberculosis H37Rv by allelic exchange. J. Bacteriol. 181:4780-4789.

Pizarro-Cerdá J., Méresse S., Parton R.G., Goot G., Aola-Landa A., Lopez-Goñi I., Moreno E. \& Gorvel J.P. 1998. Brucella abortus transits through the autophagic pathway and replicates in the endoplasmic reticulum of non professional phagocytes. Infect. Immun. 66:57115724.

Poester F.P., Gonçalves V.S.P., Paixão T.A., Santos R.L., Olsen S.C., Schurig G.G. \& Lage A.P. 2006. Efficacy of strain RB51 vaccine in heifers against experimental brucellosis. Vaccine 24:5327-5334.

Rolán H.G., Xavier M.N., Santos R.L. \& Tsolis R.M. 2009. Natural antibody contributes to host defense against an attenuated Brucella abortus virB mutant. Infect. Immun. 77:3004-3013.

Rosinha G.M.S. 2002. Isolamento, idenficação e avaliação do envolvimento dos genes gap, pgk, tkt, vacB e exsA da Brucella abortus na patogênese molecular e imunoproteção. Tese de Doutorado em Bioquímica, Instituto de Ciências Biológicas, Departamento de Bioquímica e Imunologia, Universidade Federal de Minas Gerais, Belo Horizonte, MG. 226p.

SAS Institute 2005. Statistical Analysis System User's Guide. Version $9^{\text {th }}$ ed. SAS Institute Inc., Carym p.5123.

Sieira R., Comerci D.J., Sánchez D.O. \& Ugalde R.A. 2000. A homologue of operon required for DNA transfer in Agrobacterium is required in Brucella abortus for virulence and intracellular multiplication. J. Bacteriol. 182:4849-4855.

Verguer J.M., Grimont F., Grimont P.A.D. \& Grayon M. 1985. Brucella A monospecific genus as shown by deoxyribonucleic acid hybridization. Int. J. Syst. Bacteriol. 35:292-295.

Watarai M., Makino S. \& Shirahata T. 2002. Na essencial virulence protein of Brucella abortus, virB4, required na intact nucleside-triphosphatebinding domain. Microbiol. 148:1439-1446.

Wu Q., Jianwu P., Turse C. \& Ficht T.A. 2006. Mariner mutagenesis of Brucella melitensis reveals genes with previously uncharacterized roles in virulence and survival, BMC. Microbiology 6:102.

Yang X., Becker T., Walters N. \& Pascual D.W. 2006. Deletion of znuA virulence factor attenuates Brucella abortus and confers protection against wild-type challenge. Infect. Immun. 74:3874-3879. 